Pesq. Vet. Bras. 37(7):701-707, julho 2017

DOI: $10.1590 / \mathrm{S} 0100-736 \mathrm{X} 2017000700009$

\title{
Avaliação da infectividade parasitária a Lutzomyia longipalpis por xenodiagnóstico em cães tratados para leishmaniose visceral naturalmente adquirida ${ }^{1}$
}

\author{
Gabriela Nery ${ }^{2 *}$, Dinah R.D. Becerra² ${ }^{2}$ Lairton S. Borja ${ }^{3}$ Jairo T. Magalhães-Junior ${ }^{2}$, \\ Bárbara M.P.S. Souza ${ }^{4}$, Carlos R. Franke ${ }^{2}$, Patrícia S.T. Veras ${ }^{3}$, Daniela F. Larangeira ${ }^{2,5}$ \\ e Stella Maria Barrouin-Melo ${ }^{2,5 *}$
}

\begin{abstract}
Nery G., Becerra D.R.D., Borja L.S., Magalhães-Junior J.T., Souza B.M.P.S., Franke C.R., Veras P.S.T., Larangeira D.F. \& Barrouin-Melo S.M. 2017. [Evaluation of parasite infectivity for Lutzomyia longipalpis by xenodiagnosis in dogs treated for natural visceral leishmaniasis.] Avaliação da infectividade parasitária a Lutzomyia longipalpis por xenodiagnóstico em cães tratados para leishmaniose visceral naturalmente adquirida. Pesquisa Veterinária Brasileira 37(7):701-707. Laboratório de Infectologia Veterinária, Escola de Medicina Veterinária e Zootecnia, Universidade Federal da Bahia, Av. Adhemar de Barros 500, Salvador, BA 40170-110, Brazil. E-mail: gabinery@hotmail.com

The outcome of a multidrug chemotherapeutic protocol against canine visceral leishmaniasis (VL) has been evaluated for its effect on dogs' capacity of transferring Leishmania infantum to sand flies by xenodiagnosis. Thirty-five naturally infected dogs were examined before and during treatment with a combination of metronidazole, ketoconazole, and allopurinol, at every three months up to one year. For each evaluation, treated dogs were individually submitted to xenodiagnosis and quantitative PCR to quantify parasite load in sand flies. The treatment was effective in blocking parasite transmission from host to sand flies $(p=0.011)$ in the assessed dogs. There was a significant correlation between clinical improvement and sand fly infectivity: dogs that achieved better clinical conditions showed a lower chance of $L$. infantum transference to vector by xenodiagnosis ( $\mathrm{r}=0.528, \mathrm{p}=0.002)$. These results demonstrate that the treatment of dogs with the proposed protocol may represent an alternative to dog culling in Brazil for disease control, since these drugs are not used for treating human VL in endemic areas.
\end{abstract}

INDEX TERMS: Parasite infectivity, Lutzomyia longipalpis, xenodiagnoses, dogs, visceral leishmaniasis, Leishmania infantum, multidrug chemotherapy, quantitative PCR.

\footnotetext{
${ }^{1}$ Recebido em 24 de junho de 2015.

Aceito para publicação em 30 de março de 2017.

${ }^{2}$ Laboratório de Infectologia Veterinária, Escola de Medicina Veterinária e Zootecnia (MEVZ), Universidade Federal da Bahia (UFBA), Av. Adhemar de Barros 500, Salvador, BA 40170-110, Brasil. E-mails: dinahbecerra@ gmail.com, lairtonsb@yahoo.com.br, jairomev@gmail.com, babiparana@ yahoo.com.br, frankeufba@gmail.com, pveras@bahia.fiocruz.br, daniela. larangeira@ufba.br; *Autor para correspondência: gabinery@hotmail. com e barrouin@ufba.br

${ }^{3}$ Laboratório de Patologia e Biointervenção, Centro de Pesquisa Gonçalo Moniz-Fundação Oswaldo Cruz, Rua Waldemar Falcão 121, Candeal, Salvador, BA 40296-710, Brasil.

${ }^{4}$ Laboratório de Biologia Celular e Molecular, MEVZ-UFBA, Av. Adhemar de Barros 500, Salvador, BA 40170-110, Brasil.

${ }^{5}$ Departamento de Anatomia, Patologia e Clínicas, MEVZ-UFBA, Av. Adhemar de Barros, 500, Salvador, BA 40170-110, Brasil.
}

RESUMO.- 0 efeito de um protocolo quimioterápico multidrogas contra a leishmaniose visceral (LV) canina, sobre a capacidade de transmissão de Leishmania infantum ao vetor, foi analisado por meio de xenodiagnóstico. Trinta e cinco cães naturalmente infectados foram avaliados antes e durante o tratamento com a combinação de metronidazol, cetoconazol e alopurinol a cada três meses por até um ano. Em cada avaliação, os cães foram individualmente submetidos ao xenodiagnóstico e quantificação da carga parasitária por PCR quantitativa. 0 tratamento foi eficaz em bloquear a transmissibilidade parasitária do cão para o flebotomíneo $(p=0,011)$ nos cães avaliados. Houve significante correlação entre recuperação clínica e infectividade: cães com melhora clínica mais evidente apresentaram menores chances de transferir L. infantum ao Lutzomyia longipalpis via xeno- 
diagnóstico $(r=0,528, p=0,002)$. Esses resultados demonstram que o tratamento canino com o protocolo proposto pode representar uma alternativa ao sacrifício de cães no Brasil como medida de controle da doença, uma vez que as drogas utilizadas não são aplicadas ao tratamento da LV humana em áreas endêmicas.

TERMOS DE INDEXAÇÃO: Transmissão parasitária, Lutzomyia longipalpis, xenodiagnose, caninos, visceral leishmaniose, Leishmania infantum, quimioterapia multidrogas, PCR quantitativa.

\section{INTRODUÇÃo}

A leishmaniose visceral (LV), causada por Leishmania (L.) infantum, é uma zoonose transmitida pela picada do inseto vetor Lutzomyia longipalpis (Lutz \& Neiva 1912). Endêmica em 79 países, a doença ocorre principalmente em países em desenvolvimento, como o Brasil, onde o número de casos notificados tem aumentado. Nos últimos anos (2009-2013) foram registrados 17.377 casos humanos de LV no país, sendo que a região nordeste apresentou $47,78 \%$ dos casos, seguida pelas regiões norte $(19,05 \%)$, sudeste $(16,08 \%)$, centro-oeste $(8,86 \%)$ e sul $(0,1 \%)$ (Brasil 2014).

De acordo com o Manual de Vigilância e Controle da Leishmaniose do Brasil (Brasil 2006), o controle da LV baseia-se no diagnóstico e tratamento precoce dos casos humanos, redução da população de flebotomíneos, eliminação dos cães reservatórios e atividades de educação em saúde. Porém, a prática da eutanásia de cães tem sido a principal medida empregada, mesmo sendo essa medida considerada eticamente questionável (Passantino et al. 2010, Costa 2011). Em áreas onde a eutanásia de cães soropositivos é praticada eventual ou sistematicamente para controle da LV, as taxas de incidência e letalidade da doença vêm aumentando nos últimos anos no Brasil (Quinnell \& Courtenay 2009, Barreto et al. 2011). Assim, considera-se que nas últimas décadas, milhares de cães foram sacrificados com pouco ou nenhum impacto na expansão da doença (Dantas-Torres 2007, Quinnell \& Courtenay 2009, Passantino et al. 2010, Costa 2011).

Diversos autores vêm criticando a eficácia da eutanásia de cães soropositivos sobre a redução da incidência de casos humanos e caninos (Dantas-Torres 2007, Quinnell \& Courtenay 2009, Maroli et al. 2010, Costa 2011). Além disso, a literatura aponta evidências de que o tratamento dos cães poderia ser uma alternativa para o combate à doença, uma vez que cães tratados apresentam redução da carga parasitária e da infectividade para flebotomíneos (Gradoni et al. 1987, Alvar et al. 1994, Ribeiro et al. 2008, Miró et al. 2011, Da Silva et al. 2012). No entanto, o tratamento de cães é objeto de discussão no Brasil, estando proibido pelos órgãos de saúde pública com o argumento de que o tratamento canino provoca resistência do parasito ao medicamento usado no tratamento humano e, que, até o momento, não há um tratamento que bloqueie a transmissão do parasito do cão ao vetor (Brasil 2006).

Com poucas alternativas, os veterinários brasileiros que optam pelo tratamento estão adotando protocolos alternativos, fazendo uso de drogas que não são utilizadas no tratamento da LV humana, para evitar resistência do parasito ao medicamento, como os derivados do imizol, como o metronidazol e o cetoconazol. Estes medicamentos antifúngicos agem contra certos tipos de bactérias e parecem ter potencial antiprotozoárico em agentes anaeróbios. Estas drogas agem sobre o metabolismo proteico, inibindo a síntese do ergosterol e de ácidos nucléicos pelo bloqueio da 14-demetilase. Também atuam intensificando a glicogenólise e diminuindo as reservas de glicogênico, o que provoca a morte do protozoário (Amusategui et al. 1995). No entanto, apesar da eficiência contra Leishmania ser estudada desde a década de 1980, o mecanismo de ação destas drogas não está completamente esclarecido. Por não serem utilizados no tratamento da LV humana, são uma boa opção para o tratamento da LV canina (Amusategui et al. 1995, Pennisi et al. 2005).

Em 2016, em Nota Técnica conjunta, no 001/2016, os Ministérios da Agricultura Pecuária e Abastecimento (MAPA) e da Saúde (MS) autorizaram o registro do produto Milteforan ${ }^{\circledR}$, principal droga utilizada no tratamento da LVC na Europa e que não é utilizada no tratamento da doença humana no Brasil. No entanto, o Conselho Federal de Medicina Veterinária (CFMV), continua a declarar, até o momento, que não há nenhuma droga autorizada para o tratamento da LVC (CFMV 2016). Desta forma, ainda há necessidade de desenvolvimento de protocolos para o tratamento de cães que não incluam drogas utilizadas para o tratamento de casos de LV humana.

O objetivo do presente estudo foi avaliar por até um ano, por meio da técnica de xenodiagnóstico, a transmissibilidade parasitária de cães tratados com metronidazol, cetoconazol e alopurinol contra a leishmaniose visceral.

\section{MATERIAL E MÉTODOS}

Protocolo terapêutico e desenho experimental. 0 tratamento aplicado aos cães do presente estudo foi realizado sob a forma de associação de múltiplas drogas e padronizado para todos os cães, conforme dados da literatura (Amusategui et al. 1995, Pennisi et al. 2005). As drogas associadas foram o cetoconazol (10mg/kg, SID, via oral (VO), durante 40 dias consecutivos); o metronidazol (20mg/kg, BID, VO, durante 30 dias consecutivos) e o alopurinol (10mg/kg, BID, VO, durante 12 meses a partir do trigésimo dia).

Os cães tratados foram monitorados em até cinco avaliações: pré-tratamento - dia zero (D0) e aos 90 (D90), 180 (D180), 270 (D270) e 360 (D360) dias após o início do tratamento. Em cada avaliação foi realizado exame clínico completo, coleta de sangue para patologia clínica e xenodiagnóstico, sob sedação com acrepromazina a $1 \%(1 \mathrm{mg} / \mathrm{kg})$ pela via intravenosa.

Os exames de patologia clínica realizados foram hemograma completo (Kit Bioeasy, Brasil) e bioquímica sérica que incluíram creatinina, alanina aminotransferase (ALT), fosfatase alcalina, proteínas totais, albumina e globulinas (Kit Doles, Brasil).

No D0, foi coletado amostra de aspirado esplênico, de acordo com a técnica padronizada por Barrouin-Melo et al. (2006), para realização de cultivo celular para diagnóstico parasitológico da doença.

Animais e aspectos éticos. Cães provenientes de área endêmica e com suspeita clínica de LVC foram submetidos a todos os procedimentos do presente estudo no Hospital de Medicina Veterinária da Universidade Federal da Bahia (Hospmev-UFBA). 
Os critérios de inclusão no estudo foram cães atendidos no Hospmev-UFBA com positividade na cultura de aspirado esplênico (Barrouin-Melo et al. 2006) e/ou na PCR quantitativa de aspirado esplênico (Francino et al. 2006, Solcà et al. 2014) para LV canina (dados não publicados) e o guardião ter interesse em tratar seu cão. Todos os guardiões assinaram um termo de consentimento, livre e esclarecido. Por razões éticas, não houve um grupo positivo não tratado, sendo a avaliação pré-tratamento determinada como controle para comparação com os dados obtidos durante o monitoramento terapêutico de 12 meses. Todos os cães foram mantidos domiciliados com seus respectivos guardiões. 0 uso de coleira impregnada com deltametrina contra flebotomíneos (Scalibor $^{\circledR}$, MSD Saúde Animal, Brasil) foi recomendado durante todo o período do estudo para evitar reinfecção dos cães.

0 presente estudo teve a aprovação da comissão de ética no uso de animais da Escola de Medicina Veterinária e Zootecnia da UFBA, sob o protocolo no 19/2011.

Estadiamento clínico. Em cada avaliação, os cães foram examinados individualmente e agrupados de acordo com o comprometimento clínico e com as anormalidades nos dados de patologia clínica, associados à LV, com base na categorização proposta pelo Leishvet group (Solano-Gallego et al. 2011) adaptada para a realidade local (Quadro 1). Dessa forma, os cães foram classificados em três Estágios, em que o Estágio 1 foi composto por cães infectados e sem alterações clinicas e laboratoriais no momento do exame; o Estágio 2 correspondeu aos cães infectados e com alterações clínicas e laboratoriais brandas; o Estágio 3 incluiu cães infectados com alterações clínicas e laboratoriais severas.

Xenodiagnóstico para verificação de transferência parasitária do cão para o vetor. 0 xenodiagnóstico foi realizado para avaliação da capacidade de transferência de Leishmania infantum do cão para o vetor Lutzomyia longipalpis.

Cultivo de flebotomíneos para o procedimento xenodiagnóstico. Foram utilizados adultos de L. longipalpis provenientes da colônia do insetário do Laboratório de Infectologia Veterinária da UFBA. A colônia foi inicialmente formada por flebotomíneos capturados no município de Ipecaetá $\left(12^{\circ} 18^{\prime} 00^{\prime} \mathrm{S} 39^{\circ} 18^{\prime} 28^{\prime} \mathrm{W}\right)$, estado da Bahia, e vem sendo cultivada de maneira fechada seguindo metodologia descrita por Modi e Tesh (1983), com algumas modificações. Insetos pertencentes às gerações 12 a 21 foram utilizados nos exames xenodiagnósticos nos cães.

Foram utilizados 35 fêmeas e 15 machos acondicionados em recipientes específicos de $4 \mathrm{~cm}$ de altura e $3 \mathrm{~cm}$ de diâmetro telados com malha fina.

Após a alimentação, os flebotomíneos foram transferidos para gaiolas próprias onde foram mantidos durante cinco dias no insetário, recebendo apenas alimentação açucarada. Ao final do período, os insetos foram acondicionados em tubos estéreis de 1,5mL e mantidos a $-20^{\circ} \mathrm{C}$ para posterior extração de DNA e pesquisa de Leishmania por PCR quantitativa (qPCR). 0 objetivo do xenodiagnóstico neste estudo foi a avaliação da capacidade de transferência de formas parasitárias do cão para o inseto vetor, portanto, o

\section{Quadro 1. Categorização dos cães atendidos no HOSPEMV- UFBA entre 2012-2014 com leishmaniose visceral em 3 estágios de acordo com o comprometimento clínico e de patologia clínica, baseado no estadiamento proposto pelo Leihvet Group (Solano-Gallego et al. 2011) com alterações para a realidade local}

\footnotetext{
Estágio 1 Sem doença clínica ou doença clínica branda + sem anemia + proteína total normal ou alterada

Estágio 2 Sem doença clínica ou doença branda + sem ou com anemia + proteína total alterada

Estágio 3 Doença severa + com anemia + proteína total alterada
}

tempo que os insetos foram mantidos após o repasto sanguíneo não interfere no resultado.

Procedimento xenodiagnóstico no cão. Três dias antes do procedimento, foi retirada do cão a coleira impregnada com deltametrina e os animais foram banhados com sabão neutro, sendo vedado o uso de qualquer outro produto repelente no cão até o dia do exame. Após procedimento de sedação, os cães foram posicionados em decúbito lateral, e os recipientes aplicados em contato com a face interna do pavilhão auricular durante 30 minutos para os insetos realizarem o repasto sanguíneo.

Diagnóstico e quantificação da transferência parasitária a flebotomíneos por PCR quantitativa. O DNA foi obtido a partir do grupo de flebotomíneos, por cão, utilizados no xenodiagnóstico com o Kit comercial Purelink Genomic DNA Mini Kit ${ }^{\circledR}$ (Promega), seguindo as instruções dos fabricantes. Após a extração, as amostras de DNA foram ajustadas à concentração final de 10ng/ $\mu \mathrm{L}$, aliquotadas e mantidas no freezer de $-20^{\circ} \mathrm{C}$ até a realização do teste. A qPCR das amostras do pool de flebotomíneos, técnica previamente padronizada e descrita por Francino et al. (2006) e Solcà et al. (2014), foi realizada para quantificar e avaliar a variação da infectividade dos cães aos flebotomíneos entre D0 e D360. Para minimizar as variações entre as placas, os valores obtidos em cada placa foram normalizados a partir de um Threshold Cycle (Ct) comum. $\mathrm{O}$ valor do $\mathrm{Ct}$ de cada amostra foi calculado com base na determinação do ponto em que a fluorescência gerada na reação excedeu o threshold. Para determinação do Ct definido como ponto de corte, a reação de amplificação para kDNA de Leishmania foi realizada utilizando na mesma placa DNA extraído de 20 cães controle negativos da área não endêmica para LVC, Pelotas (RS), e de 20 cães positivos em exames parasitológicos, provenientes da área endêmica de Jequié (BA). Para calcular o valor do Ct da reação para detecção em flebotomíneos de DNA de Leishmania, amostras de DNA de flebotomíneos foram utilizadas como controle negativo e amostras de DNA de flebotomíneos misturadas ao DNA de Leishmania foram utilizados como controle positivo. Uma curva ROC foi construída e o ponto de corte correspondeu àquele que forneceu os maiores valores de sensibilidade e especificidade para o teste. 0 ponto de corte da reação foi de 370 e 35,2, para baço e flebotomíneos, respectivamente, correspondendo a uma sensibilidade de 100\% e especificidade de $95 \%$ (Solcà et al. 2014). Os resultados obtidos na reação foram expressos para 50 ng de DNA de pool de flebotomíneos e foram padronizados para $1 \mathrm{mg}$ de DNA.

Análise estatística. A análise estatística foi feita por meio de comparação entre os resultados dos períodos D0-D90, D90-D180, D180-D270 e D270-D360. As variáveis não paramétricas do estadiamento clínico e das cargas parasitárias esplênica e dos flebotomíneos foram analisadas utilizando o teste Wilcoxon. Para avaliar se houve correlação estatística entre os parâmetros analisados, foi utilizado teste de Spearman. As análises foram consideradas significativas quando $\mathrm{p}<0,05$ (SPSS v. 17.0).

\section{RESULTADOS}

\section{Características dos cães do estudo}

Trinta e cinco cães preencheram os critérios de inclusão e foram submetidos ao tratamento, para leishmaniose visceral, e ao xenodiagnóstico, sendo 16 eram machos e 19 fêmeas. A média de idade desses animais foi de 4,2 anos, variando entre 7 meses e 12 anos. A maior parte não tinha raça definida (41,4\%), seguido por Rotweiller, Pastor Alemão, Labrador e Boxer (14\% cada). A maioria era composta por cães de guarda, expostos naturalmente à infecção no ambiente externo, que viviam em áreas endêmicas, prin- 
cipalmente no Litoral Norte da Bahia (69,2\%), mas também foram atendidos animais provenientes de Salvador $(20,5 \%)$, Feira de Santana $(2,6 \%)$, Ilha de Itaparica $(2,6 \%)$ e Jequié $(2,6 \%)$. Um animal $(2,6 \%)$ foi proveniente de Roraima $(2,6 \%)$, região também conhecida como endêmica.

Devido aos óbitos (5) e às desistências dos guardiões em levar os animais para repetir os exames, o número de animais durante as avaliações foi reduzido sendo 35, 33, 22 e 16 no D90, D180, D270 e D360, respectivamente. Porém, em algumas avaliações, nem todos os cães foram submetidos a todos os exames.

\section{Estadiamento clínico}

No D0, $66,7 \%$ dos cães foram categorizados no Estágio 2 , apresentando sinais clínicos e laboratoriais brandos da doença. Ao longo das avaliações houve melhora progressiva nesses parâmetros. 0 número de cães categorizados no Estágio 1 aumentou, enquanto houve diminuição do percentual de cães nos Estágios 2 e 3, ocorrendo diferença estatística entre D0-D90 ( $\mathrm{p}=0,000)$ (Fig.1).

\section{Infectividade canina por meio da transferência parasi- tária ao inseto vetor}

Os resultados dos exames xenodiagnósticos mostraram que a capacidade de transmitir o parasito ao inseto vetor, ou infectividade, apresentou uma tendência a decrescer, até alcançar a nulidade durante as avaliações dos cães sob tratamento. No D0, 50\% (19/38) dos cães apresentaram resultados positivos na qPCR de flebotomíneos, no D90 a positividade diminuiu para $11,4 \%(4 / 35)$, no D180, $16,1 \%$ (5/31) dos cães eram capazes de transmitir parasitos ao vetor, no D270 a infectividade diminuiu para 10\% (2/20)

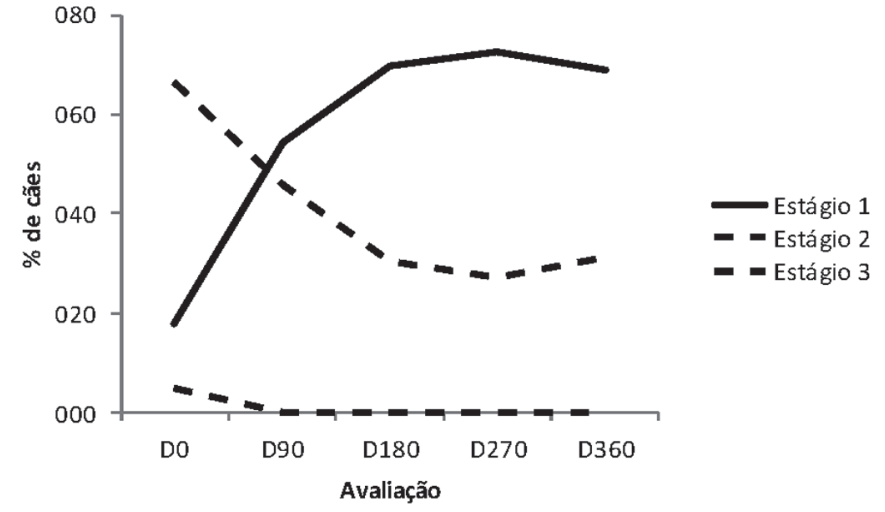

Fig.1. Evolução do estadiamento clínico dos cães atendidos no Hospemv-UFBA entre 2012-2014, naturalmente infectados por Leishmania infantum e tratados contra leishmaniose visceral. Os cães foram agrupados conforme as avaliações realizadas no D0, D90, D180, D270 e D360 e o resultado foi expresso em percentual de cães que foram categorizados em estágio 1 (cães sem doença clínica/doença clínica branda, com anemia e proteína total normal ou alterada); estágio 2 (cães sem doença clínica /com doença clínica branda, sem ou com anemia e com proteína total alterada, estágio 3 (cães com doença severa, com anemia e com proteína total alterada)

dos cães e no D360 nenhum cão transmitiu Leishmania a $L$. longipalpis no xenodiagnóstico (Quadro 2).

A carga parasitária dos flebotomíneos utilizados nos xenodiagnósticos apresentou também uma redução gradativa durante as avaliações, apresentando diferença estatística entre D0-D90 (P=0,025) e D0-D360 (P=0,011). No D0, a mediana da carga parasitária foi de $1,9 \times 10^{5}$ Leishmania $/ \mathrm{mg}$

Quadro 2. Evolução da carga parasitária dos flebotomíneos submetidos ao xenodiagnóstico em cães atendidos no HOSPEMV-UFBA entre 2012-2014, naturalmente infectados por Leishmania infantum em cinco avaliações: antes do tratamento (D0) e 90 (D90), 180 (D180), 270 (D270) e 360 (D360) dias após o início do tratamento. A positividade foi determinada pela presença de parasitos em flebotomíneos de xenodiagnóstico em qPCR. Os resultados estão expressos de acordo com cada um dos animais avaliados (A1-A35) em positivos (+), negativo (-), não realizado (NR) e morte (OB)

\begin{tabular}{|c|c|c|c|c|c|c|c|c|c|c|c|}
\hline & $\frac{\text { D0 }}{(34)^{*}}$ & $\frac{\mathrm{D} 90}{(35)^{*}}$ & $\begin{array}{l}\text { D180 } \\
31)^{*}\end{array}$ & $\begin{array}{l}\mathrm{D} 270 \\
20)^{*}\end{array}$ & D360 & & $\frac{\text { D0 }}{(34)^{*}}$ & $\frac{\mathrm{D} 90}{35)^{*}}$ & D180 & $\begin{array}{l}\text { D270 } \\
201 *\end{array}$ & $\frac{\text { D360 }}{15)^{*}}$ \\
\hline $\mathrm{A} 1$ & + & - & + & NR & NR & A19 & - & - & - & - & NR \\
\hline A2 & + & - & - & NR & - & A20 & - & - & + & - & - \\
\hline A3 & - & - & - & - & - & A21 & + & - & - & - & NR \\
\hline A4 & - & - & - & OB & OB & A22 & + & - & - & - & - \\
\hline A5 & + & - & - & NR & NR & A23 & + & - & - & - & NR \\
\hline A6 & - & - & - & NR & NR & A24 & - & - & - & NR & NR \\
\hline A7 & - & - & - & - & NR & A25 & + & + & - & + & NR \\
\hline A8 & - & - & - & - & - & A26 & + & - & $\mathrm{OB}$ & $\mathrm{OB}$ & $\mathrm{OB}$ \\
\hline A9 & - & + & - & - & NR & A27 & + & + & - & - & NR \\
\hline A10 & NR & - & - & NR & - & A28 & - & - & - & - & - \\
\hline A11 & + & - & - & $\mathrm{OB}$ & OB & A29 & + & - & - & - & - \\
\hline A12 & + & - & - & - & - & A30 & - & - & - & - & - \\
\hline A13 & - & - & - & - & NR & A31 & - & - & + & NR & NR \\
\hline A14 & + & - & - & NR & - & A32 & + & + & + & NR & - \\
\hline A15 & + & - & $\mathrm{OB}$ & OB & $\mathrm{OB}$ & A33 & + & - & - & - & NR \\
\hline A16 & + & - & + & + & - & A34 & - & - & NR & - & - \\
\hline A17 & - & - & NR & NR & NR & A35 & + & - & - & NR & - \\
\hline A18 & + & - & - & - & $\mathrm{OB}$ & & & & & & \\
\hline
\end{tabular}

\footnotetext{
* Número de cães submetidos ao xenodiagnóstico em cada avaliação.
} 


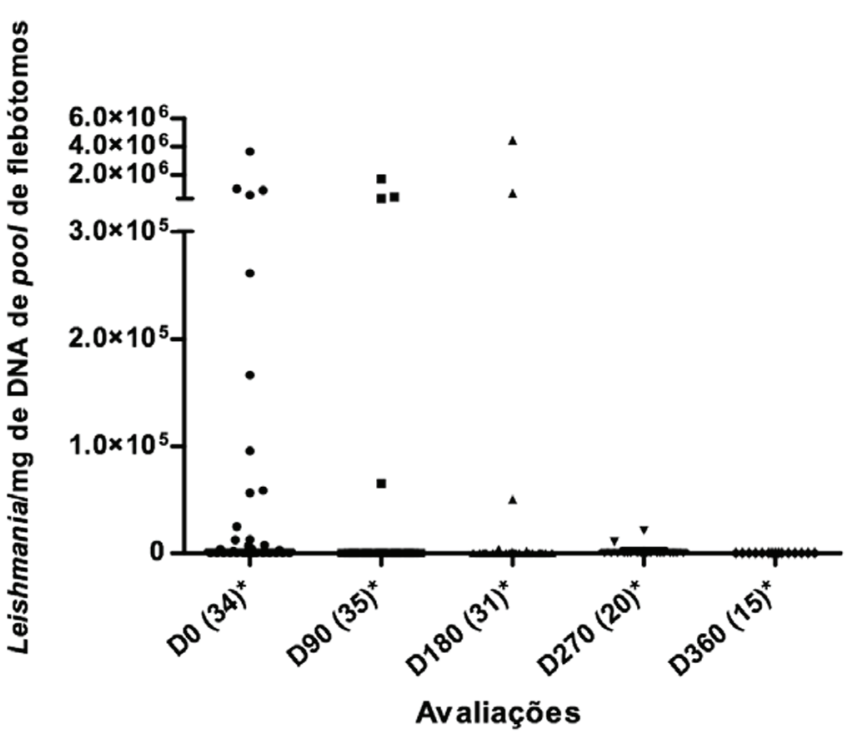

Fig.2. Evolução da distribuição da carga parasitária nas amostras de flebotomíneos submetidos ao xenodiagnóstico em cães atendidos no Hospemv-UFBA entre 2012-2014, naturalmente infectados por Leishmania infantum. Os resultados foram agrupados conforme as avaliações realizadas no D0, D90, D180, D270 e D360. 0 resultado foi obtido através da qPCR e foi apresentado pelo número de parasitos em $1 \mathrm{mg}$ de DNA de pool de flebotomíneos. A linha representa a mediana da carga parasitária de cada avaliação.

de pool de flebotomíneos por cão e diminuiu para 0 Leishmania/mg de /pool de flebotomíneos por cão a partir da avaliação D90 até a D360 (Fig.2). Houve uma tendência à diminuição da transmissibilidade à medida que o estadiamento clínico melhorou, havendo correlação estatística entre estes parâmetros no D180 $(\mathrm{r}=0,528, \mathrm{p}=0,002)$.

\section{DISCUSSÃO E CONCLUSÃo}

Nos últimos anos, principalmente a partir do ano de 2008, quando o tratamento de cães com LV foi proibido pelos órgãos governamentais de saúde pública, muito tem se discutido sobre a baixa eficácia de utilizar a eutanásia de cães soropositivos como a principal medida de controle da $\mathrm{LV}$ no Brasil (Dantas-Torres 2007, Quinnell \& Courtenay 2009, Costa 2011). Diferentes estudos apontam medidas mais eficazes que a eutanásia para o controle e prevenção da LV, como o uso de coleiras impregnadas com inseticidas, vacinação e tratamento dos cães infectados (Reithinger et al. 2004, Solano-Gallego et al. 2009, Maroli et al. 2010, Palatnik-de-Sousa 2012, Fernandes et al. 2014). Na Europa, e em todos os países onde a LV é endêmica, a eutanásia de cães soropositivos não é utilizada como medida de controle da doença e os cães infectados são rotineiramente tratados (Gradoni et al. 1987, Alvar et al. 1994, Miró et al. 2009, Miró et al. 2011, Solano-Gallego et al. 2009, Solano-Gallego et al. 2011).

No Brasil, apenas em 2016 foi autorizado a licença de uma droga para o tratamento da LVC, mas além desta ainda não estar sendo comercializada no país, o CFMV não reconhece esta autorização do MAPA/MS como válida, por não ter sido publicada no Diário Oficial, e continua declarando que, baseado na Portaria Interministerial 1426/2008, o tratamento da doença permanece proibido (CFMV 2016). Desta forma, médicos veterinários continuam sem autonomia decisória quanto ao tratamento de cães infectados. Segundo as recomendações da Brasileish, grupo de estudos formados por pesquisados brasileiros especialistas em LVC e responsáveis pela autorização da comercialização do milteforan ${ }^{\circledR}$ no Brasil, os médicos veterinários deveriam ter autonomia, baseada no conhecimento, de indicar entre o tratamento e a eutanásia (Ribeiro et al. 2013). Além disso, seria importante para o veterinário ter mais de uma opção diferente de medicamento para o tratamento da LVC.

De acordo com os resultados do presente estudo, uma melhora no estadiamento clínico foi significativa a partir do primeiro trimestre após iniciado o protocolo quimioterápico, quando mais da metade dos cães tratados passou a ser categorizada no Estágio 1, no qual os animais não apresentavam sinais clínicos da LV. Seis meses após o início, mais de $70 \%$ dos cães foram agrupados no Estágio1 e, neste momento, foi observada correlação estatística com a infectividade, demonstrando que quanto menos sinais clínicos e anormalidades laboratoriais um cão apresenta, menor o risco dele transmitir o parasito para o vetor. No entanto, não há consenso na literatura sobre essa relação. Alguns autores já observaram que animais sem sinais clínicos não transmitem o parasito (Travi et al. 2001) enquanto outros argumentam que um cão infectado pode transmitir o protozoário independentemente de apresentar ou não sinais clínicos (Michalsky et al. 2007).

Os cães que passaram a não mais transmitir parasitos para o inseto vetor no xenodiagnóstico ao longo do monitoramento foram considerados curados para efeito do presente estudo, inclusive e principalmente no parâmetro infectividade. Outros estudos resultaram em dados similares, nos quais os cães tratados apresentaram diminuição ou bloqueio da transmissibilidade parasitária, segundo seus autores (Gradoni et al. 1987, Alvar et al. 1994, Ribeiro et al. 2008, Miró et al. 2011).

Através do xenodiagnóstico, foi possível observar diminuição da infectividade dos cães ao inseto vetor nos primeiros três meses após início do tratamento, quando mais de $88 \%$ dos cães tratados passaram a não ser capazes de infectar flebotomíneos com o parasito durante o xenodiagnóstico neste estudo. No final do estudo, todos os cães avaliados apresentaram bloqueio da transmissibilidade parasitária. Em todos os estudos em que foi avaliada infectividade de cães tratados para LV, foi observada redução na infectividade dos cães, independente do protocolo terapêutico (Gradoni et al. 1987, Alvar et al. 1994, Ribeiro et al. 2008, Miró et al. 2011, Da Silva et al. 2012) inclusive após a suspensão do tratamento (Alvar et al. 1994, Ribeiro et al. 2008, Guarga et al. 2002).

0 presente estudo avaliou apenas cães que estavam sob efeito de alopurinol em até um ano após o início do protocolo multiquimioterápico. Estudos sobre a capacidade de transmissão parasitária por cães após suspensão do uso do alopurinol em nossas condições precisam ser desenvolvidos para verificar se esses animais apresentariam recidivas. No entanto, utilizando outros protocolos terapêuticos, 
alguns autores já observaram recidivas da doença após a suspensão dessa droga (Ferrer et al. 1995, Torres et al. 2010).

Há poucos trabalhos na literatura que reportaram o uso do xenodiagnóstico para avaliar a eficácia de diferentes tratamentos de cães com LV. O presente estudo é o único que realizou o seguimento clínico e xenodiagnóstico por um ano. Além disso, o presente estudo reporta dados obtidos com grande número de cães domiciliados, cujas condições e resultados podem refletir mais naturalmente condições equivalentes do público-alvo de protocolos veterinários para a abordagem clínica da doença. Miró et al. (2011) realizaram desenho experimental semelhante, mas com um menor período de tempo (6 meses). Alvar et al. (1994), apesar de terem realizado um estudo de 11 meses, o fizeram em um grupo de apenas 6 animais. Outros dois estudos (Ribeiro et al. 2008 e Da Silva et al. 2012) utilizaram grupos grandes, mas foram utilizados cães de centros de controle de zoonoses e mantidos em canis experimentais durante o estudo. Além disso, ambos os estudos foram feitos em até 150 e 200 dias após iniciado o tratamento, respectivamente. Comparativamente, Gradoni et al. (1987) e Guarga et al. (2002) utilizaram também grupos pequenos (2 e 6 cães, respectivamente) e por menos tempo que o presente estudo (150 e 180 dias, respectivamente, após início do tratamento). Podemos, então, afirmar que o presente estudo apresenta dados robustos e inéditos pelo fato de apresentar os resultados de tratamento de 35 cães naturalmente infectados, todos domiciliados, tratados com o protocolo multiquimioterápico, ministrado pela via oral e acompanhados por 12 meses. Além disso, este é o primeiro estudo em que se avalia a eficácia do tratamento através da quantificação da carga parasitária através da qPCR de flebotomíneos utilizados no xenodiagnóstico.

Com base nas evidências apresentadas, podemos concluir que o tratamento dos cães infectados por L. infantum, utilizando a associação de cetoconazol, metronidazol e alopurinol, pode ser um indicado para o tratamento e controle da doença canina, já que resultou em diminuição da transmissibilidade do parasito do cão para o inseto vetor desde os primeiros meses de implementação e, após um ano do início do tratamento, interrompeu a transmissibilidade em $100 \%$ dos cães do estudo. 0 tratamento bem sucedido de cães pode representar uma medida importante, eficaz e ética de abordagem e combate à $\mathrm{LV}$ em áreas endêmicas. Novas pesquisas devem ser realizadas para avaliação do potencial de transmissibilidade do cão após um ano de tratamento.

Agradecimentos.- Agradecemos à Fundação de Amparo à Pesquisa do Estado da Bahia (FAPESB) pelo apoio financeiro por meio do Programa de Apoio a Núcleos Emergentes (PRONEM-FAPESB) 498/2011 - PNE 0002/2011 e pela bolsa de doutorado concedida.

Contribuição dos autores.- Gabriela Nery: responsável pela elaboração e desenvolvimento do estudo e por redigir o manuscrito; Dinah R.D. Becerra: responsável por auxiliar no desenvolvimento do estudo em todas as etapas; Lairton S. Borja: responsável pela execução dos ensaios da qPCR; Jairo T. Magalhães-Junior: responsável pelos xenodiagnóstico; Bárbara M.P.S. Souza: responsável pelas análises estatísticas e revisão do manuscrito; Carlos R. Franke, Patrícia S.T. Veras, Daniela F. Laranjeira: respon- sáveis pela coorientação do estudo e revisão do manuscrito; Stella Maria Barrouin-Melo: responsável pela elaboração e orientação do estudo e revisão do manuscrito.

\section{REFERÊNCIAS}

Alvar J., Molina R., San Andrés M., Tesouro M., Nieto J., Vitutia M., González F., San Andrés M.D., Boggio J. \& Rodríguez F. 1994. Canine leishmaniasis: clinical, parasitological and entomological follow-up after chemotherapy. Ann. Trop. Med. Parasitol. 88:371-378.

Amusategui I., Sainz A., Rodriguez F. \& Tesouro M.A. 1995. Tratamento de la leishmaniosis canina. Medicina Veterinária12:289-298.

Barreto M., Teixeira M.G., Bastos F., Ximenes R.A.A., Barata R.B. \& Rodrigues L.C. 2011. Sucessos e fracassos no controle das doenças infecciosas no Brasil: o contexto social e ambiental, políticas, intervenções e necessidades de pesquisa. Lancet: 47-60.

Barrouin-Melo S.M., Larangeira D.F., Santos S.O., Chagas-Junior A.D., Paixão M., Aguiar P.H., Dos-Santos W.L. \& Pontes-De-Carvalho L. 2006. A standardized cytological and immunochemical method for the analysis of fine-needle spleen aspirates: assessment of leukocyte population changes in canine visceral leishmaniosis. Vet. Immunol. Immunopathol. 111:251-261.

Brasil. 2006. Manual de Vigilância e Controle da Leishmaniose Visceral. Secretaria de Vigilância em Saúde. Departamento de Vigilância Epidemiológica, Ministério da Saúde, Brasília. 113p.

Brasil 2014. Portal da Saúde SUS (Sinan/SVS/MS). Ministério da Saúde, Brasília. Disponível: <http://tabnet.datasus.gov.br/cgi/deftohtm. exe?idb2011/d0205.def> Acesso em 18 nov. 2014.

CFMV 2016. Conselho Federal de Medicina Veterinária. Disponível em <http://portal.cfmv.gov.br/portal/noticia/index/id/4794/secao/6> Acesso em 25 out. 2016.

Costa C.H. 2011. How effective is dog culling in controlling zoonotic visceral leishmaniasis? A critical evaluation of the science, politics and ethics behind this public health policy. Revta Soc. Bras. Med. Trop. 44:232-242.

Dantas-Torres F. 2007. The role of dogs as reservoirs of Leishmania parasites, with emphasis on Leishmania (Leishmania) infantum and Leishmania (Viannia) braziliensis. Vet. Parasitol. 149:139-146.

Da Silva S.M., Amorim I.F., Ribeiro R.R., Azevedo E.G., Demicheli C., Melo M.N., Tafuri W.L., Gontijo N.F., Michalick M.S. \& Frézard F. 2012. Efficacy of combined therapy with liposome-encapsulated meglumine antimoniate and allopurinol in treatment of canine visceral leishmaniasis. Antimicrob. Agents Chemother. 56:2858-2867.

Ferrer L., Aisa M.J., Roura X. \& Portus M. 1995. Serological diagnosis and treatment of canine leishmaniasis. Vet. Rec. 136:514-516.

Fernandes C.B., Junior J.T., de Jesus C., Souza B.M., Larangeira D.F., Fraga D.B., Tavares Veras P. \& Barrouin-Melo S.M. 2014. Comparison of two commercial vaccines against visceral leishmaniasis in dogs from endemic areas: IgG, and subclasses, parasitism, and parasite transmission by xenodiagnosis. Vaccine 32:1287-95.

Francino O., Altet L., Sanchez-Robert E., Rodriguez A., Solano-Gallego L., Alberola J., Ferrer L., SAnchez A. \& Roura X. 2006. Advantages of real-time PCR assay for diagnosis and monitoring of canine leishmaniosis. Vet. Parasitol. 137:214-221.

Gradoni L., Maroli M., Gramiccia M. \& Mancianti F. 1987. Leishmania infantum infection rates in Phlebotomus perniciosus fed on naturally infected dogs under antimonial treatment. Med Vet Entomol. 1:339-342.

Guarga J.L., Moreno J., Lucientes J., Gracia M.J., Peribanez M.A. \& Castillo J.A. 2002. Evaluation of a specific immunochemotherapy for the treatment of canine visceral leishmaniasis. Vet Immunol Immunopathol. 88:13-20.

Lutz A. \& Neiva A. 1912. Contribuição para o conhecimento das espécies do gênero Phlebotomus existentes no Brasil. Mem. Inst Oswaldo Cruz 4:84-95.

Maroli M., Gradoni L., Oliva G., Castagnaro M., Crotti A., Lubas G., Paltrinieri S., Roura X., Zini E. \& Zatelli. 2010. Guidelines for prevention of leishmaniasis in dogs. J. Am. Vet. Med. Assoc. 236:1200-1206.

Michalsky E.M., Rocha M.F., Da Rocha Lima A.C.V.M., França-Silva J.C., Pires M.Q., Oliveira F.S., Pacheco R.S., Dos Santos S.L., Barata R.A. \& Romanha 
A.J. 2007. Infectivity of seropositive dogs, showing different clinical forms of leishmaniasis, to Lutzomyia longipalpis phlebotomine sand flies. Vet. Parasitol. 147:67-76.

Miró G., Galvez R., Fraile C., Descalzo M.A. \& Molina R. 2011. Infectivity to Phlebotomus perniciosus of dogs naturally parasitized with Leishmania infantum after different treatments. Parasites Vectors 4:52.

Miró G., Oliva G., Cruz I., Cañavate C., Mortarino M., Vischer C. \& Bianciardi P. 2009. Multicentric controlled clinical study to evaluate effectiveness and safety of miltefosine and allopurinol for canine leishmaniosis. Vet. Dermatol. 20:397-404.

Modi G.B. \& Tesh R.B. 1983. A simple technique for mass rearing Lutzomyia longipalpis and Phlebotomus papatasi (Diptera: Psychodidae) in the laboratory. J. Med. Entomol. 20:568-569.

Palatnik-de-Sousa C.B. 2012. Vaccines for canine leishmaniasis. Frontiers in Immunology 3:1-15.

Passantino A., Russo M. \& Coluccio P. 2010. Canine leishmaniosis and euthanasia in Italy: a critical legal-ethical analysis. Revta Scient Technol. 29:537-548.

Pennisi M.G., De Majo M., Masucci M., Britti D., Vitale F. \& Del Maso R. 2005. Efficacy of the treatment of dogs with leishmaniosis with a combination of metronidazole and spiramycin. Vet. Rec. 156:346-349.

Quinnell R.J. \& Courtenay O. 2009. Transmission, reservoir hosts and control of zoonotic visceral leishmaniasis. Parasitology 136:1915-1934.

Reithinger R., Colemana P.G., Alexanderb B., Vieirac E.P., Assisc G. \& Daviesa G.R. 2004. Are insecticide-impregnated dog collars a feasible alternative to dog culling as a strategy for controlling canine visceral leishmaniasis in Brazil? Int. J. Parasitol. 34:55-62.

Ribeiro R.R., Moura E.P., PimenteL V.M., Sampaio W.M., Silva S.M., Schettini
D.A., Alves C.F., Melo F.A., Tafuri W.L., Demicheli C., Melo M.N., Frézard F. \& Michalick M.S. 2008. Reduced tissue parasitic load and infectivity to sand flies in dogs naturally infected by Leishmania (Leishmania) chagasi following treatment with a liposome formulation of meglumine antimoniate. Antimicrob. Agents Chemother. 5:2564-2572.

Ribeiro V.M., Da Silva S.M., Menz I., Tabanez P., Nogueira F.S., Werkhaüser M., Da Fonseca A.L.S. \& Dantas-Torres F. 2013. Control of visceral leishmaniasis in Brazil: recommendations from Braz. Parasites Vectors 6:8.

Solano-Gallego L., Koutinas A., Miró G., Cardoso L., Pennisi M.G., Ferrer L., Bourdeau P., Oliva G. \& Baneth G. 2009. Directions for the diagnosis, clinical staging, treatment and prevention of canine leishmaniosis. Vet. Parasitol. 165:1-18.

Solano-Gallego L., Miró G., Koutinas A., Cardoso L., Pennisi M.G., Ferrer L., Bourdeau P., Oliva G. \& Baneth G. 2011. LeishVet guidelines for the practical management of canine leishmaniosis: rewiew. Parasites Vectors $4: 86$.

Solcà M.S., Bastos L.A., Guedes C.E.S., Bordoni M., Borja L.S., Larangeira D.F., Da Silva Estrela Tuy P.G., Amorim L.D.A.F., Nascimento E.G., De Sá Oliveira G.G., Dos-Santos W.L.C., Fraga D.B.M. \& Veras P.S.T. 2014. Evaluating the accuracy of molecular diagnostic testing for canine visceral leishmaniasis using latent class analysis. Plos One 9:e103635.

Torres M., Bardagí M., Roura X., Zanna G., Ravera I. \& Ferrer L. 2010. Long term follow-up of dogs diagnosed with leishmaniosis (clinical stage II) and treated with meglumine antimoniate and allopurinol. Vet. J. 188:346-51.

Travi B.L., Tabares C.J., Cadena H., Ferro C. \& Osorio Y. 2001. Canine visceral leishmaniasis in Colombia: relationship between clinical and parasitologic status and infectivity for sand flies. Am. J. Trop. Med. Hyg. 64:119-124. 